\title{
Discussion on São Paulo Mobility Plans
}

\author{
A. MeSQuita ${ }^{1}$, F. MAES $^{2}$, M. MoraIS ${ }^{3}$ \\ 1University of Debrecen, Faculty of Engineering, engmesquitaamanda@gmail.com \\ ${ }^{2}$ University of Debrecen, Faculty of Engineering, maes.fernandalucia@gmail.com \\ 3University of Debrecen, Faculty of Engineering, marianabdemorais@gmail.com
}

Since urbanization rising and urban demographic increase, urban transportation has been an important life quality aspect and a strategic decision for cities. Mobility seems to follow citizens behavior and be influenced by urban cultural changes in the same pace it influences back the city routine and resident's conduct. The discussion around the future of mobility gained new magnitude nowadays, since some sort of vehicles have proved themselves as the cause of significant environmental impact, while others showed themselves as alternatives of low impact for different reasons - from quality public transportation to individual transport with minimized emissions. The city of São Paulo in Brazil published its Master Plan in 2014 and its Mobility Plan in 2015, analyzing the current situation and proposing a future to the city's transportation system. This paper intends to analyze both plans, construe the popular participation in their formulation and application, discuss how data and strategy were presented and whether they are aligned with other countries' thinking on the subject. As a city of over 10 million inhabitants, in a Metropolitan Region of 39 cities with over 20 million inhabitants, the transportation system of São Paulo is not an easy or singlesolution issue. It is known the need for a combination of different transportation modes, requiring likewise new visions for all methods. Owing to the fact that modes complete each other and, in that manner, may reach a wider range of options for the population to plan daily life, then a system with great variety of modes ensures the best functioning of them all. This paper focus on an outsider view that searches for answers and solutions on the São Paulo transportation system, having as base what is considered outstanding in the world for this issue.

Keywords: Mobility, public transport, urban planning, walking, cycling.

\section{Introduction}

Urban mobility is directly interconnected with cities urbanization process, which started in Brazil around 1930, due to the arrival of large industries. This impact also accelerated the migration progression of the population from rural to urban areas, searching for jobs and quality of life improvement.

As cities began to present an exacerbated number of people and few jobs, urban problems began to rise during this period. Both urban planning and mobility plans - public transport - in Brazil were not able to keep up with such population growth, causing several problems to this day.

São Paulo is a clear example of this abrupt change in the Brazilian scenario. The state capital has several urban and mobility issues, including chaotic traffic and crowded public transport. This brings the necessity to rethink and develop strategies and plans to improve city's urban mobility and mitigate such problems. Therefore, in recent years the city has been preparing its Master Plan (2014) [1] and Urban 
Mobility Plan (2015) [2], always seeking the collaboration of the population in its process, as in the preparation of the most recent Master Plan.

To better understand the current challenges related to urban mobility, it is necessary to understand how the course of development and evolution of Brazilian cities happened, focusing on the Metropolitan Region of São Paulo, which is one of the biggest agglomerations in the world. Thus, a brief historical context will be presented, as well as the laws covering the subject, and its bibliographic review.

This article aims to raise a discussion around the plans developed for the city of São Paulo, with regard to urban mobility, to detect if they align with the same ideals used by other cities in the world. To this end, a review will be carried out with a focus on the São Paulo Master Plan [1] published in 2014, and the city's Urban Mobility Plan [2], published the following year (2015).

The whole discussion will be carried out through the analyses of the European Guidelines for Developing and Implementing a Sustainable Urban Mobility Plan (2nd Edition) [3], and the New York City - Strategic Plan 2016 of the Department of Transportation, in comparison with the measures proposed for the city of São Paulo.

\section{Literature Review}

Today the Metropolitan Region of São Paulo is one of the largest urban agglomerations in the world, with over 20 million inhabitants in 39 municipalities [2]. The emergence of São Paulo dates back many years, along with the discovery of Brazil. Although, regarding mobility, it is possible to say that the process is relatively recent, and its beginning is linked to the structural changes that occurred in the Brazilian economy and society in the 1930s, mainly due to the arrival of large industries.

It was from 1950 that São Paulo started to face the peak of urban acceleration, which also has a major impact on urban mobility in the country. From the same decade, due to the strong presence of the automobile industry, numerous policies in federal, state and municipal spheres, were created aiming the strengthening of this industries, such as the construction of highways, the adoption of traffic engineering focused on the flow of automobiles, financing programs for vehicle purchases, among others.

Supporting the use of individual vehicles at the time, associated with the low efficiency and quality of public transport, especially automobiles, resulted in a modal split that accounted for about more than $50 \%$ of travels made by individual trips at the beginning of the turn of this century, which corresponds to the opposite of the scenario considered ideal [2].

Until 1970 it is possible to observe the accelerated growth of the region, but this year had a certain slowdown in the process. It is also noted that from 1970 an exchange takes place in the city's economic base. There is a loss of strength in the Industrial sector and, on the other hand, the Commerce and Services sector emerges, becoming the most important economic activity of the municipality since then.

In Brazil, the laws that assist mobility, and deals with these urban problems reflected today, are the following:

- Law 10.257/2001: it is the Statute of Cities that establish general guidelines for Brazil's Urban policy and requires the creation of Master Plans for many municipalities. [5] 
- Law 12.587/2012: which governs the guidelines of the National Urban Mobility Policy, also called the Urban Mobility Law, it determines the municipalities the task of planning and executing the urban mobility policy. [6]

- Law 13.089/2015: known as the Metropolis Statute, this law establishes general guidelines for the planning, management, and execution of public functions of common interest in metropolitan regions and urban agglomerations. [7]

- Law 13.683/2018, which brought minor changes to the two previous laws. [8]

The Statute of Cities is a Federal Law number 10,257 of June 10, 2001 [5], which aims to establish general guidelines for Brazil's Urban policy. In that time, it was needed to organize urban spaces in the face of rapid population growth and inadequate land distribution. According to Pinho e Brito [9], in 1980 around $68 \%$ of total Brazil's population was living in urban areas, in 1991 the rate of urbanization was $75 \%$, and in 2000 it was around 81\%. This rapid urban growth has led to several problems for urban centres, including the lack of infrastructure.

The "Constitution of the Federative Republic of Brazil" was promulgated in 1988. It was the seventh constitution of Brazil since its Independence, and in 1822 the sixth of the republican period. This Federal Constitution started to deal with urban law and dedicated a specific chapter to urban policy. In short, this chapter requires an urban property to fulfil its social function. It says that is up to the union to set the general guidelines for urban policy and, for the municipalities, to formulate and execute their policy according to these guidelines, by elaborating a Master Plan [1].

The Statute of Cities [5] was created with the objective of regulating articles 182 and 183 of the Urban Policy Chapter of the Federal Constitution [10]. It establishes general guidelines and offers tools for municipalities to put them into practice, brings together important urban, tax and legal instruments that can guarantee effectiveness to the Master Plan, responsible for the establishment of urban policy in the municipal sphere. The Master Plan of a city, in it turns, is a law that must be approved by the Chamber, and which is the basic instrument of municipal policy development and urban expansion.

In January of 2012, the Federal Law N. 12,587 was enacted, which established the National Urban Mobility Policy - PNMU [6]. This Law determined that all municipalities over 20 thousand inhabitants must prepare an urban mobility plan. This law also deals with item XX of art. 21 and art. 182 of the Federal Constitution and aims to integrate the different modes of transport and improve accessibility and mobility for people and cargo within the municipality and prioritizes public transport modes and active modes.

\subsection{Master Plan of São Paulo 2014}

The Law 16.050/2014 created the last Master Plan [1] of the Municipality of São Paulo, in order to make it a modern and better place, rebalancing and humanizing the city. The plan, based on a strong participatory review, intended to bring jobs closer to dwelling homes. This revision happened during one and a half year with over 114 meetings and 25,000 participants.

The objective of the type of presentation chosen for the Master Plan, was to expand and facilitate the population's access to the contents of the new law. For that reason, it was elaborated a presentation of 
the 10 strategies of the plan in an illustrated format. A simple, easy-to-understand way, that arouses interest and increases public participation in what is being proposed, with the aim that they request for its execution.

\subsubsection{Urban Mobility improvement}

The Master Plan [1] addresses urban mobility based on integration and articulation between different media transport. Establishes minimum and permanent resources to expand the network and qualify public transport and non-motorized means of transport (system cycling and pedestrian circulation), less pollutants. It also recognizes new components of the urban mobility system (logistics system, waterway, and car sharing) for structuring a more displacement matrix comprehensive, efficient and environmentally balanced. [1]

The plan aims to enable urban mobility through:

- A motivated public transport - Expansion and better qualification of the public transport system (e.g. bus runners), to reduce daily commuting time and promote accessibility to different regions of the city;

- Placement of funds from the Urban Development Fund (FUNDURB) - At least 30\% of the FUNDURB will be used to implement public transport, bicycle and pedestrian circulation system;

- Wide sidewalks - Minimum width of 5 meters in bus corridors and 3 meters in the areas of influence;

- A Municipal Urban Mobility Plan - With the definition of guidelines and deadlines for the participatory elaboration of the plan, as well as in the Master Plan, it will take into consideration the existing conditions, actions for amplification, integration and qualification of the transport system, also monitoring mechanism and encouraging actions to reduce environmental impact;

- Implementation of new mobility systems - With the intention of structuring an articulated and efficient displacement matrix, logistics and cargo, waterway and car sharing will be recognized.

- The plan show through images what are the goals to be achieved, such as: prioritizing public transport (Figure 1), expanding the urban mobility network (Figure 2), integrating transport, discouraging individual motorized transport, reducing pollution and encouraging car sharing. 


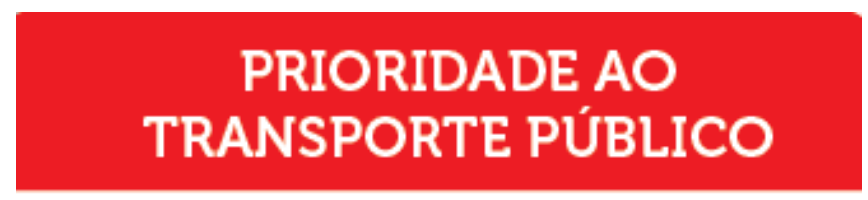

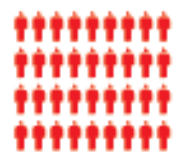

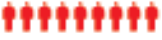

tritititit

ititititit

ifipititit

itipitipi

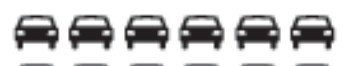

回昌回回回

คด同国

国昌国星昌

으요요

30 automóveis

Figure 1. Prioritizing urban transport ${ }^{1}$

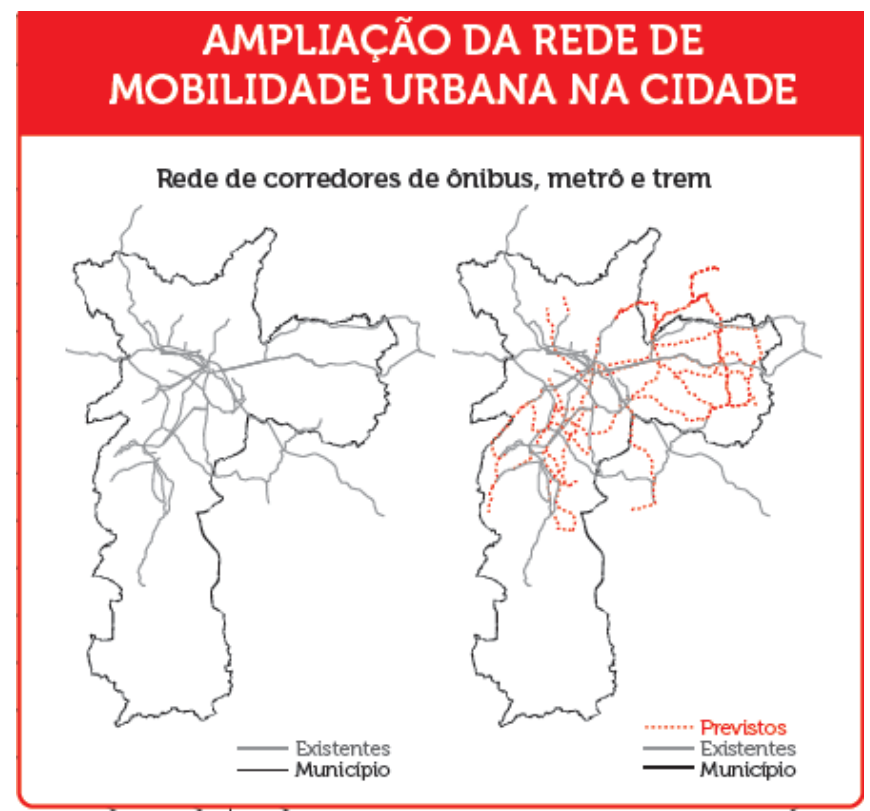

Figure 2. Expanding the urban mobility network ${ }^{1}$

The Figure 2 shows the network of bus, subway, and train corridors. The black line is the delimitation of the county, the blue line is the network already existent and in dotted red is the network already planned for the next years. The next image illustrates how the plan might work and what are their ideas to be implemented. 


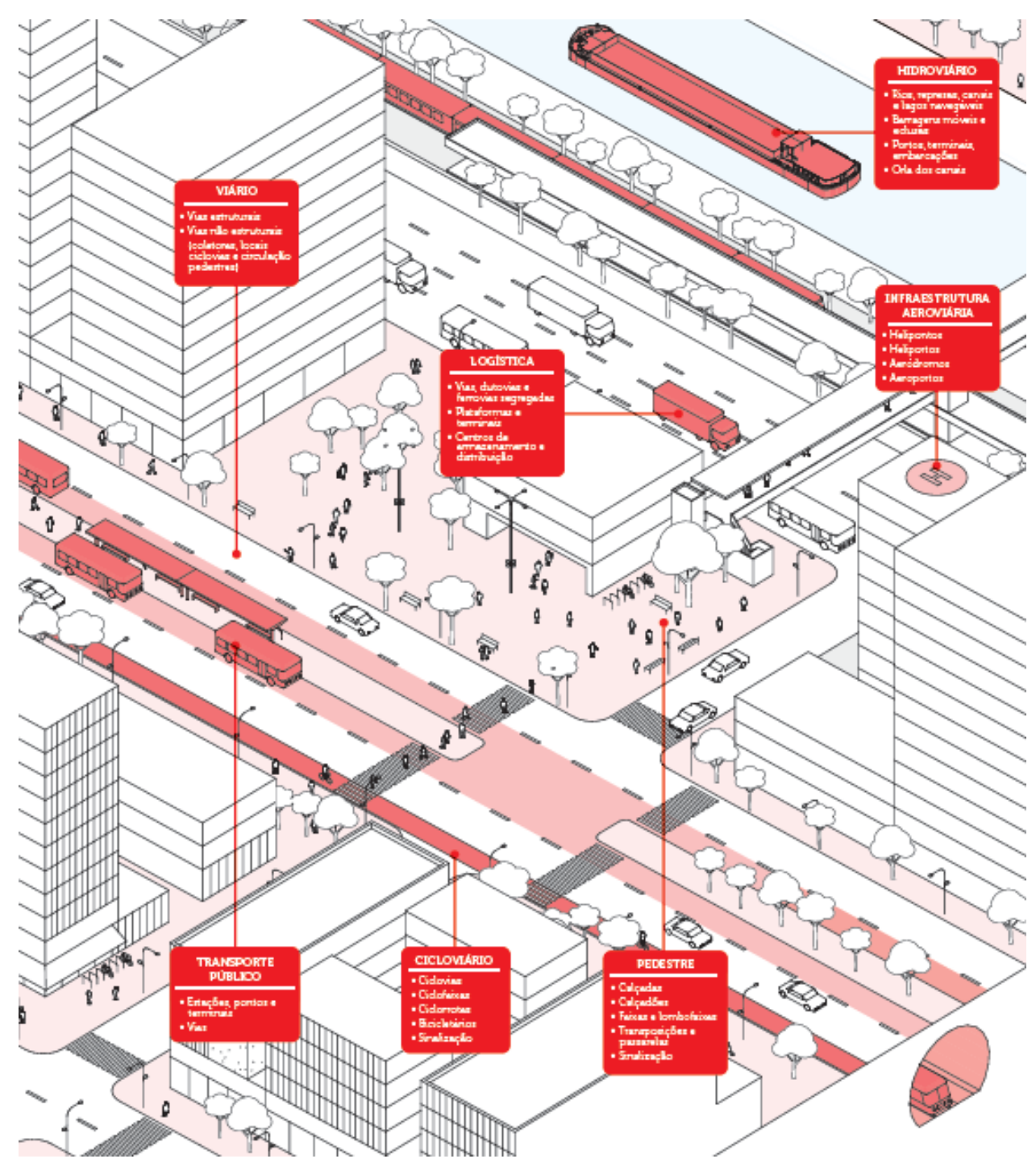

Figure 3. Illustration of the Plan ${ }^{1}$

As challenges, they will face the difficulty in transforming the transport network in a more balanced way, creation of mechanisms that guarantee accessibility for all and minimize environmental impacts and the reduction of the need for long daily displacement of the population through the approximation between employment and housing. But to deal with them, the plan is to prioritize public transport and non-motorized modes of travel, directing the city growth near public transport, sources of permanent funding and elaboration of the Municipal Mobility Plan.

The fundamental key to making São Paulo a more humanized city is improving the circulation of pedestrians and cyclists. For that, actions that prioritize the expansion and improvement of sidewalks, pedestrian crossings, walkways and living spaces, bike lanes, bike racks and bicycle sharing mechanisms will be developed and implemented. All this from FUNDURB.

The Master Plan determines that the Municipal Urban Mobility Plan should be elaborated in a in a participatory way. It needs to guide the mobility policy based on the analysis of existing accessibility and mobility conditions, establish actions to expand and improve the Public Transport System, make 
programs for managing the roads, implement parking lots in strategic areas of the city, have tariff guidelines (especially for low-income populations), ensure universal accessibility, and reduce environmental impacts and measures for each of the urban mobility systems.

\subsection{São Paulo Urban Mobility Plan - PlanMob/SP 2015}

Elaborated between 2013 and 2015, PlanMob aims to portray the Urban Mobility System [2] and indicate principles, guidelines, and actions to be taken. Future actions and measures will also be mentioned that are fundamental complements and that may not be included in the technical outline of the plan, since the emergence of new technologies, processes and data may directly interfere in their application and good development.

The relationship between the Master Plan [1] and the Urban Mobility Plan [2] is intrinsic. The areas destined to the densification of employment and housing activities need a medium and high-capacity transport network, for that reason it is recommended to reduce the large number of motorized commuting trips at the municipal level. Another focus will be the prioritization of the use of road space for public road transport and the link between transport policies of cities in the metropolitan region of São Paulo, as their economies are interdependent, as well as the transport between them.

The mobility plan reports the general urban mobility indicators through a survey carried out by METRO [17] which makes several comparisons between the years 1987 and 2012. According to data analysis, the total number of trips per day between 1997 and 2012 in São Paulo increased by 35\% and the number of trips/day per inhabitant increased from 1.99 to 2.33 trips, as a result of economic growth and an increase in the number of jobs. The modal division of travel was also analysed and with that it can be seen that there was a relative growth in the use of public transport in relation to the individual (in 2012 it was $56.21 \%$ for public transport versus $43.79 \%$ for private transport), going against the historical trend in the largest cities in Brazil. The growth was so great between 2007 and 2012 that it resulted in a significant worsening in the conditions of displacement of the population, both due to the lack of transportation, as well as the increase in travel time, which increased both in the collective and in the individual. Finally, it analysed the participation of walking by the population, giving importance to the promotion of minimum conditions so that the walk is of quality, with a good standard of sidewalks and safety.

\section{Discussion}

The discussion surrounding the mobility plans for the city of São Paulo is systematically divided between pointing out the main proposals and ideas behind the city planning at first, and in the sequence backing up the analysis with the research of other mobility studies worldwide.

\subsection{Urban Mobility Plan Proposals for São Paulo}

In São Paulo, between 2007 and 2012, it was observed that there was an increase of almost twice the travel time in public transport in relation to individual transport, thus prioritizing the population to 
prefer individual transport, since buses are always crowded due to lack of fleet, with high cost and low user comfort, influencing people's modal choice. This is aggravated by its operational characteristics, with little priority for its circulation in the existing road system in 2012. Therefore, the Mobility Plan ${ }^{2}$ proposes that the city government prioritize public transport in the existing road system, as a way of reducing travel time and avoiding loss of passengers.

Travel time inequality is directly related to economic inequality. The METRO study [17] shows that in São Paulo, the higher the income, the greater the participation of individual transport, with more than $80 \%$ in the use of individual transport by class $\mathrm{A}$ and in contrast of almost $90 \%$ in the use of public transport by classes D and E. Because there is a status associated with the use and possession of cars, and analysing modal participation when considering social classes, it is extremely important to implement measures to discourage these thoughts and promote the migration of individual to collective transport.

The mobility plan [2] on the other hand, transcends the government mandate, which differs from the Brazilian tradition mentioned above. With goals to be achieved by 2028, the plan proposes several measures aimed at improving mobility in São Paulo, as well as suggesting a solution to some problems.

In sequence, the proposals are discussed individually.

\subsubsection{Public Transport System}

Historically public transport in São Paulo has undergone several changes. Initially, it followed the logic of connecting each neighbourhood to the central region of the city, to meet the demand of the population that was moving towards the focus of economic activities and jobs. However, over time this model proved to be economically unfeasible due to the fact that the lines in the main corridors overlapped, being operationally inefficient. The system was changed to the trunk-fed format to improve the organization of services and, with that, integration terminals were implemented, facilitating the transfer of passengers between the bus lines, as well as the payment of a single fare that made it possible to make more than one travel by ticket. Yet, this system also presented problems, since several integration terminals and radial bus corridors were with a fatigued capacity because of the organized model and the growing number of trips on routes towards the city centre.

In operation in 2015, the urban bus system in the Municipality of São Paulo, had a fleet of 15,000 vehicles that carried 125 million paying passengers per month. In the mobility plan, there was a need to restructure and reorganize the public transport system, in order to structure the urban space as intended by the Master Plan in 2014, that is, to obtain urban mobility conditions that improve living conditions in the city and boost the economy by linking multiple sub-centres and areas of influence. For this reason, after verifying the problems with the trunk-fed system, the mobility plan suggests the implementation of a network service. Proposing that public transport services need to be dimensioned according to the hours of greatest load, distinguished according to the variation of the days of the week and times of the day, in addition to a new set of bus lines serving both the most significant regional hubs and the most peripheral areas of the city, avoiding overlaps. The new system will be more economical, faster and with a larger mesh of lines. 


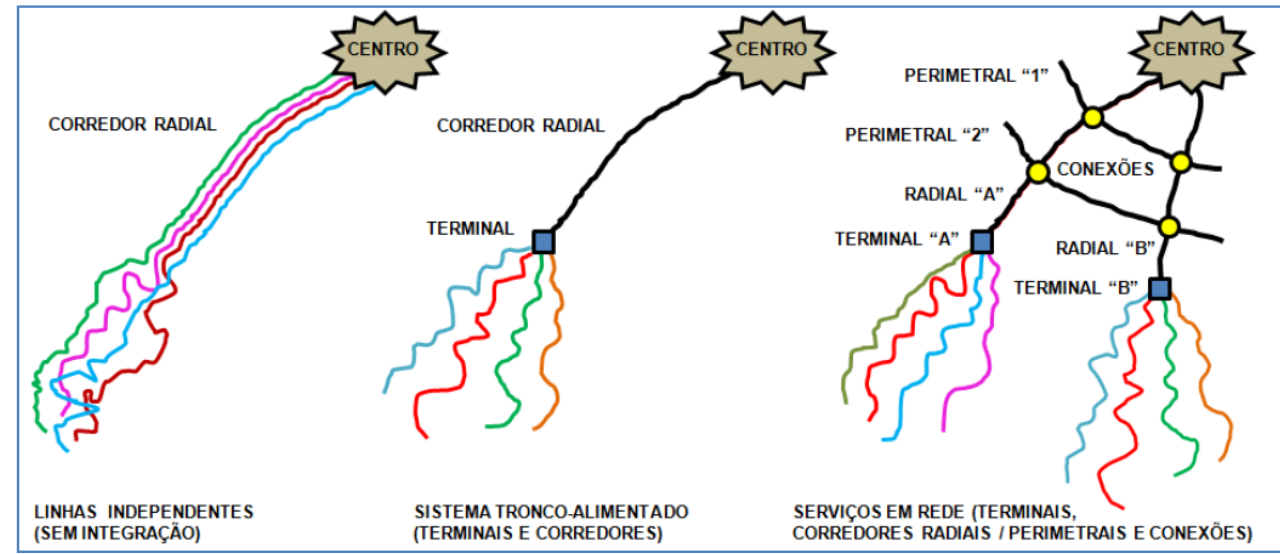

Figure 4. Evolution of the trunk model fed to the network model ${ }^{2}$

Among the main proposals subject to this new plan are the creation of $150 \mathrm{~km}$ of corridors every four years, in order to reach the $600 \mathrm{~km}$ corridor mark in 2028; prioritization of public transport through exclusive lanes; creation of new terminals and creation of a "controlled operation" to monitor transport.

\subsubsection{Active Transport - Cycling mode}

PlanMob/SP 2015 [2] encourages active mobility to benefit users and the city, promoting environmental, economic, social and health gains. Until 2015, São Paulo had $365 \mathrm{~km}$ (with plans to reach $400 \mathrm{~km}$ by the end of 2016) of routes for cyclists in the urban road system. The Mobility Plan wants to increase this number to $600 \mathrm{~km}$ by 2028 , the year in which the city will have $1,000 \mathrm{~km}$ of cycle paths, in addition to the concession of public and campaigns to encourage its use.

The use of bicycles generates social, urban and environmental benefits [11]. It expands the options for mobility and access to the city, improves the quality of life, increases security, urban centres become more attractive and reduces air, noise and air pollutants. vibrations. Among the objectives of the Cycling System, in the PlanMob/SP 2015 [2], are comfort and safety for cyclists in fairness with other road users and improving the attractiveness of the bicycle mode. The constructive elements include the Structural Cycle Network, the bicycle sharing system and the implementation of parking lots for them.

In order to favour public transport, the plan promotes that the planned public transport stations and terminals have the implementation of bicycle racks in their projects. In this way, the citizen who uses a bicycle and needs to travel greater distances, can thus have availability of public transport, as well as a safe place to leave their bicycle. The plan also promotes the use of shared bicycles, which can offer a very efficient transport alternative for a portion of the population, serving both for integration with public transport and for exclusive trips. The goal is to reach $100 \%$ of the city's territory by 2028 .

\subsubsection{Active Transport - Walking mode}

PlanMob / SP 2015 [2] put the guarantee of universal accessibility first, prioritizing walking at any time, place, or condition. Any investment in infrastructure for pedestrian walking must precede any other investment in the road, being that the basic right of the citizen to walk freely is promoted through sidewalks and spaces that allow the accomplishment of shifts on foot with quality and safety. The pedestrian movement infrastructure must bring together qualities such as: road and public safety, comfort, good conservation, lighting, continuity, connectivity, attractiveness and universal accessibility. 
The subject of sidewalks in Brazil is part of a complex discussion between the division of responsibilities (municipality and property owner and in São Paulo is no different. According to PlanMob / SP 2015 [2]:

Municipal Law No. 15.442/2011 [12] establishes that the maintenance of roads in the city's structural road system and those identified by the municipal administration as priorities for the recovery of sidewalks, under the Emergency Sidewalk Program - PEC are the responsibility of the city, while the sidewalks of the collecting and local roads are the responsibility of the owners of the neighbouring properties. [12]

This disparity results in poor management of sidewalks, as well as poor quality sidewalks and dangerous for the citizen. The plan mentions that of the 35,000 km of sidewalks, $98 \%$ present irregularities and end up causing approximately 100,000 falls annually and consequently a medical expense in the order of R \$ 3.5 billion. With this data in mind, PlanMob/SP 2015 [2] emphasizes that the management of the public road space should be unique and under the exclusive responsibility of the municipality. To this end, a survey by SMT was also taken into account, in which $60 \%$ of the population who completed the survey think that sidewalks are a public area and that the City Hall must bear all the responsibilities.

Among the plan's goals are:

- Adopt the Emergency Sidewalk Plan - PEC as an action program for the renovation, construction and adaptation of sidewalks in the city;

- Propose legislation that establishes the city hall as responsible for the construction, renovation and adjustments of the city's sidewalks; and

- Introducing a minimum walking width standard compatible with pedestrian flows in circulation.

\subsubsection{Individual Motorized Transport}

According to the plan, 44\% of motorized trips in São Paulo are made by individual transport. Due to the high numbers, generating increased congestion and travel times, high rates of air pollution, high rate of accidents and victims of traffic violence, São Paulo's mobility system has been revised in recent years.

The plan emphasizes that there has been an increase, since 2007, in the population's motorization rate. In 2017 the rate was 193 cars per thousand inhabitants, in 2012 it increased to 222. In order to discourage the use of individual motorized transport and alleviate the problems caused by it, in 1997, the Municipality of São Paulo implemented the Operation Peak Hour to perform car rotation, with the intention of mitigating the effects of traffic congestion and the quality of the city's air. The operation consists of prohibiting the circulation of two final numbers of license plates each weekday, during peak hours between 7:00 am and 10:00 am and between 5:00 pm and 8:00 pm, in regions considered critical for vehicle traffic of the city [2].

Among the individual paid public transport in the public interest are taxis and the latest Uber and Cabify that have a communication system that assures the user the confidence that the service will be available for the requested moment, as well as the payment method. PlanMob [2] reports that, in 2015, the city had a taxi for 350 inhabitants and New York City has a taxi for 650 inhabitants. 


\subsection{Reference Studies}

With the purpose of analysing the plans for the future of mobility in São Paulo, this study sought worldwide parameters as support. Studies were analysed about mobility in Brazil, but also outside of country spectrum, enabling a broad view of mobility planning in the world. A guideline for European cities - Guidelines for Developing and Implementing a Sustainable Urban Mobility Plan (2nd Edition) [3] - and a mobility plan for New York City - New York City Strategic Plan 2016 (Department of Transportation) [4] - were studied in comparison with the proposals for the city of São Paulo, construing If they take the same path and focus on similar accomplishments.

On the article "Urban Mobility: A Challenge for Public Managers", Manoel Reis [13] brought the urgency for mobility discussions in Brazil and the impact of that in the legislation, implying on the National Urban Mobility Policy (PNMU):

Due to the importance assumed by urban mobility in Brazil, the federal government created the National Urban Mobility Policy (PNMU - Law 12.587/2012), which requires all Brazilian municipalities with more than 20 thousand inhabitants to draw up a mobility plan until April 2015. Cities that do not meet the correct PNMU deadline or guidelines will be prevented to receive more federal funds for urban mobility. [13]

Political involvement is one of the thriving forces about mobility decisions. In Brazil, governmental decisions have turned the country development into the direction of car as the main transport mode. However, the Brazilian population in its integrity do not have the same opportunity of access cars. Social inequality is major issue in the country [14] and, as several other areas of life quality, the transportation system also must be planned for all Brazilians.

As pointed by Reis the low quality and little offer of public transport, added to the credits created to facilitate the acquisition of individual motorized vehicles - including an increase on the number of motorcycles on the streets, accelerated the deterioration of urban mobility through the overloaded transportation infrastructure. Buses tend to minimize the infrastructure utilization, yet not enough vehicles are disposed to the population, usually in not the best conditions. Urban trains and metros are considerable options, once they do not compromise street space and are high-capacity modes. However, the construction process demands elevated investments, captive lines, and different levels of access, implicating in loss of mobility flow. Cycling is also a possible mode to be explored, if improvement can be made on the infrastructure, such as bike lanes, since the cycler's safety is not granted without lanes.

As pointed by Manoel Reis on "Urban Mobility: A Challenge for Public Managers", the Brazilian transport systems suffers with the national political changing over the years: "the truly involvement of public managers is needed with the theme and the development of state plans, and not exclusively of government plans, which cycles are insufficient for the development of projects of this nature" [13]. The statement refers to the difference in plans made for last longer than a public manager mandate, and those made to be finished before new elections. The latter can ensure the credit of the project's results to be given to those who were in charge by the time they were made, while the former would better fit citizen's needs.

The immobility problem is also present in the major metropolis of the country, with emphasis on the article "Barriers and (im)mobility in Rio de Janeiro" in which Motte-Baumvol, Bonin, Nassi and BeltonChevallier [15] (2015, p.1) report that there is $46 \%$ of immobility on a given day in Rio de Janeiro. This 
value is related to physical or symbolic barriers, as well as the age, income, and type of activity of the population that refrains from travel on a given day. People who usually travel on foot (poor and inactive) suffer consequences on the effects of physical barriers, which force them to make detours on their paths, generating more effort, when public transport is not viable for them due to the high cost. Social fragmentation is another factor to cause immobility, mentioned in this article. The Urban Transport Master Plan for the Metropolitan Region of the State of Rio de Janeiro: Result of the source-destination survey [16] presents important data on the relationship between gender, age, education, and income of the population. These data can also be found in the document "METROPOLITAN REGION OF SÃO PAULO: Research Origin and Destination 2017" [16], while the Mobility Plan of São Paulo does not mention these factors. In 2007 São Paulo had an immobility rate of 31.7\% (a rate that dropped to 29.9\% in 2017), with $27 \%$ being men and $36 \%$ women, the main conditions of activities were due to the sick leave, retirement, lack of work and housewives, more than $45 \%$ were illiterate or with incomplete primary education, $62 \%$ were over 60 years old and $40 \%$ with family income up to $\mathrm{R} \$ 1,908$. Rio had a rate of $46.6 \%$ of immobility, $40.4 \%$ men and $52.1 \%$ women, more than $67 \%$ had more than 60 years and more than $54 \%$ of the population who practiced immobility had an income of up to 2 minimum wages.

The concept of transport planning for Europe is well designed on Guidelines for Developing and Implementing Sustainable Urban Mobility Plan [3]. Some principles were set in the document: Plan for sustainable mobility in the "functional urban area"; Cooperate across institutional boundaries; Involve citizens and stakeholders; Assess current and future performance; Define a long-term vision and a clear implementation plan; Develop all transport modes in an integrated manner; Arrange for monitoring and evaluation; Assure quality.

São Paulo does not cover all the principles established on the Guideline, however most of the points quoted are somehow represented in the plans for the city. The first point is planning for sustainable mobility in the "functional urban area" and that is possible to assess in the plans made for the city of São Paulo, when the daily trip from home to work and the commuting are taken into consideration in the planning. Cooperation across institutional boundaries is the second point in the guideline, however this one is not so clear in São Paulo plans. There are important data provided by different institutions, crucial for the development of the plan, beyond that it is not clear the opinion or cooperation between other institutions or stakeholders in the planning discussion. Once that said, the third point can be assessed with the same arguments, since it describes the involvement of citizens and stakeholders in the plan. The enquiry of the population in developing the Master Plan for the city of São Paulo was significant and is clear in the document generated, while in the Mobility Plan this participation was not described with the same relevance. The fourth point is to assess current and future performance, and again, it is not a clear path described in the plan. Current performance is the main debate of the project, concluding a set of proposals to improve mobility in the city. However, the plan sight is focused on solving current problems, not planning long-term solutions or a profound change in how the city deals with mobility. That leads to the next point, to define a long-term vision and a clear implementation plan, which is not a concise idea in the project. There is description of the implementation process, with a time goal for different markers (such as kilometres of bike lanes, square meters of sidewalks, number of bus terminals), but not a step-by-step chronogram, with a clear set of smaller projects to be executed, which area should receive attention first and the sequence after that, etc. The main principles for a long-term vision can be deduced, such as reduction of the car use, the increase on the number of public transport 
and bike users, a more walkable and safer city, yet the projects presented represent the first steps to accomplished basic levels of the main goals, what is expected to solve current problems, not a welldescribed and concise plan encompassing the long-term vision for a sustainable mobility. To develop all transport modes in an integrated manner is the next point in the Guideline. Which is an issue discussed extensively in the planning of São Paulo, such as integrating bike parking to bus terminals, improve the quality of sidewalks, connect buses and urban trains. At this point is important to indicate once again the size of the city in area and population, also how large is the commuting area and how difficult it is to arrange the mobility in a city with this proportions. There is an enormous quantity of bus lines, train lines, car lanes, and neighbourhoods to connect, even when discussing only the functional urban area. The last two points are: to arrange for monitoring and evaluation and to assure quality. Those points discuss monitoring and re-evaluation of the plan, how it develops, what could accomplish in time and what works or should be reshaped. São Paulo's planning sets a period of four years to each goal, being those cumulative, in other words, the first goal is part of the second goal and so consequently. As discussed before, would be expected a more detailed chronogram, with areas being pointed as of urgent care, or even projects arranged according to its scale and need for other projects to start.

Another issue debated in the Guideline is the evolution on planning transport systems. The figure below, presented on the document "Guidelines for Developing and Implementing Sustainable Urban Mobility Plan" [3] shows the difference between Traditional Transport Planning and Sustainable Urban Mobility Planning in several aspects.

\begin{tabular}{|c|c|c|}
\hline Traditional Transport Planning & & Sustainable Urban Mobility Planning \\
\hline Focus on traffic & $\rightarrow$ & Focus on people \\
\hline $\begin{array}{l}\text { Primary objectives: } \\
\text { Traffic flow capacity and speed }\end{array}$ & $\rightarrow$ & $\begin{array}{l}\text { Primary objectives: } \\
\text { Accessibility and quality of life, including social equity. } \\
\text { health and environmental quality, and economic viability }\end{array}$ \\
\hline Mode-focussed & $\rightarrow$ & $\begin{array}{l}\text { Integrated development of all transport modes and shift } \\
\text { towards sustainable mobility }\end{array}$ \\
\hline Infrastructure as the main topic & $\rightarrow$ & $\begin{array}{l}\text { Combination of infrastructure, market, regulation, } \\
\text { information and promotion }\end{array}$ \\
\hline Sectoral planning document & $\rightarrow$ & Planning document consistent with related policy areas \\
\hline Short and medium-term delivery plan & $\rightarrow$ & $\begin{array}{l}\text { Short and medium-term delivery plan embedded in a } \\
\text { long-term vision and strategy }\end{array}$ \\
\hline Covering an administrative area & $\rightarrow$ & $\begin{array}{l}\text { Covering a functional urban area based on travel-to-work } \\
\text { flows }\end{array}$ \\
\hline Domain of traffic engineers & $\rightarrow$ & Interdisciplinary planning teams \\
\hline Planning by experts & $\rightarrow$ & $\begin{array}{l}\text { Planning with the involvement of stakeholders and citizens } \\
\text { using a transparent and participatory approach }\end{array}$ \\
\hline Limited impact assessment & $\rightarrow$ & $\begin{array}{l}\text { Systematic evaluation of impacts to facilitate learning and } \\
\text { improvement }\end{array}$ \\
\hline
\end{tabular}

Figure 5 - Differences between traditional transport planning and Sustainable Urban Mobility Planning ${ }^{3}$

Assessing São Paulo mobility plan through the table presented, in some matters it tends to a more Sustainable Mobility Planning and in others to the Traditional Transport Planning. For example, the Mobility Plano of São Paulo tends to solve traffic current problems, not so much to shift the direction of 
the planning into a human scale, into walkability as a main proposal, thinking about people comfort and safety. There is a wish to be a more walkable city, but not so many tangible individual projects to encourage that happening are presented, beyond the improvement of sidewalks and general citations on the importance of bringing people interest into walking. In that manner, it is more a traditional transport planning. For the primary objectives, it is not a clear assessment since the Plan for São Paulo stands in the middle between the two options. The quality of life and economic viability are described on the principles of the plan, still the projects are focused on solving current traffic issues. A significant principle of the plan is to integrate different transport modes, including biking and public transport. For that reason, in that point the plan tends to a more Sustainable Mobility Plan. However, the main concern of the plan is about infrastructure improvements, other projects stay in second position for attention, meaning that São Paulo is tending to a more traditional planning. As the plan takes into consideration daily trips from home to work and commuting between cities of the metropolitan region, it is consistent with the policy area designated in the table above, and consequently a Sustainable Mobility Plan. Since the strategy of the plan has a focus on solving current problems rather a long-term vision project, orienting the mobility future for the city, in that issue it is a more traditional planning. However, for the next point it is the opposite, a clear Sustainable Mobility Plan, focusing on the "functional urban area", on home-to-work trips, as explained before. Whereas the plan is authored by a public agency, it is expected that different professionals were involved in its elaboration, however this fact is not evident in the document presented. For that point, it is not clear an assessment. The next point can be described as a more traditional planning analysis since the participation of people and other stakeholders does not have a robust presence in the document. Finally, the last point is about monitoring, evaluating, and learning from the process. The plan presents a goal for every four years in which the development could be monitored, and even evaluated and rethought if needed. In that manner, the plan tends to be a Sustainable Mobility Plan, however with reservations. As pointed out before, a step-by-step chronogram, describing smaller projects involved, would be necessary for a better assessment of the plan's development.

The Master Plan for the city of São Paulo is visually clear and easily understood by the general population. In addition to this fact, popular participation is very clear in decision-making. In the opposite direction is the Mobility Plan, which does not give as much relevance to popular participation as the Master Plan, furthermore it is not as accessible to the citizens of the city of São Paulo. Manoel Reis [13] said on "Urban Mobility: A Challenge for Public Managers" that:

Mobility plans must be developed in a participatory and transparent manner, ensuring that they meet the real needs of people and make universal access to the means of travel available in the city, prioritizing non-motorized and collective transport and discouraging the use of the car. The plan should ensure that works made for mobility cease to be be punctual interventions and be part of a set that really allows changing the reality of people's displacements, democratizing the use of city space and the access to essential services. [13]

In New York City, the Department of Transportation elaborated a document with strategies for the future development of the city [4]. On the chapter dedicated to mobility, the document resumed the main goals they would focus on, being those: Increase travel by walking, biking, and bus transit; Increase bus travel speeds; Work with the Metropolitan Transportation Authority (MTA) to reduce commute times; Creating a roadway and sidewalk network that is accessible to all New Yorkers; Expand the 
availability of shared-use mobility services, including bikeshare, carshare, and rideshare; Increase the efficient use of curb space; Use sensor technology and data analytics to better enforce traffic and parking rules.

A first analysis over New York City goals can clarify that the city is moving forward mobility new concepts, as is the European Guideline. A complex of projects encourages New Yorkers to choose active modes of transportation (walking and biking) over individuals motorizes options; the public transport is being thought as interactive, both between their own modes, such as different types of buses and rail vehicles, and with other individual modes (biking and walking, for example); sharing options are highly considerate and parking rules restricted.

Both cities, São Paulo and New York City, share similarities that allows a parsing of mobility in great scales, in numbers of population and area. When comparing São Paulo with European cities, the city stands out for its large population and, therefore, complexity. There are several characteristic issues specific of the city, as its historical evolution and cultural behaviour. Matters discussed and planned with the singularities of the city. However, it is possible to set side-by-side the principles, proposals and goals of those cities and parse how their path is traced, if they aim at the same development objectives. Even though that comparison has been made above in this study, it is worth comparing the solutions presented by New York City, a city of similar magnitude, with those presented by São Paulo.

It is possible to observe the concern of both cities in bringing new solutions for public transport, their service capacity, reduction in service time, integration with other modes of transport. Sidewalks are also quoted by both as in needed of improvement to guarantee pedestrian comfort, as the plan to encourage new bikers. Sharing modes of transport is also solutions presented by both cities, such as carsharing and bike sharing, as well as concerns about environmental impacts caused by transportation. It could be concluded that similar solutions were presented in the two cases, safeguarding the different characteristics specific to each city.

The Strategic Plan for New York City presents a set of different projects that combined give a welldesigned perspective of what is expected for the city's mobility in the future, while São Paulo Plan is more focused on a smaller package of infrastructure projects with several kilometres of construction ahead.

Another difference is the chapter called The Public Realm in New York City Strategic Plan. Where is discussed the interest in make the population's occupation of the streets more feasible, comfort and pleasant. Increasing the safety, improving the land use, creating attractive public spaces. This goal would serve São Paulo as well, suggesting a change in behaviour and security patterns, potentially increasing the interest of people in active modes of transportation, and opening new possibilities of use and public interaction. This theme is not addressed in the planning of São Paulo as it is in New York City, but it could be a proposal that fits both. In this way it is possible to notice that São Paulo remains steps behind New York City in planning urban mobility. The latter is designing for a long-term change in a human scale, whilst the former still solves infrastructure issues. 


\section{Conclusion}

This study could conclude the alignment in principles between São Paulo Mobility Plan, the European Guideline, and the New York City Strategic Plan. However, the strategies proposed for São Paulo comprehend the first steps of mobility improvements, whilst Europe and New York City already discuss advanced measures. While in Europe and in New York City the documents concern about the user experience, an attempt to switch plan's direction into a path of a future pleasant, comfortable, and safe walkable city, São Paulo demonstrates a primary concern in guarantee a quality basic infrastructure.

Despite reaching the main principles, the Mobility Plan of São Paulo visual interaction with readers is less attractive than the other documents analysed, even more than the Master Plan, once is not presented as accessible or easily understandable. Making clear which are the step-by-step projects involved in the plan would give a better perspective on achieving the proposed general goals. In that manner, monitoring and evaluating the development of the plan would be more objective, consequently improving the learning process from the steps already achieved.

\section{References}

[1] Lei 16.050/14, Aprova a política de desenvolvimento urbano e o plano diretor estratégico do município de são paulo e revoga a lei no 13.430/2002. Secretaria do Governo Municipal (de 31 de Julho de 2014).

[2] Decreto 56.834, institui o plano municipal de mobilidade urbana de são paulo - Planmob/SP 2015, Secretaria do Governo Municipal, (de 24 de Fevereiro de 2016).

[3] Guideline for Developing and Implementing Sustainable Urban Mobility Plan, Second Edition. European Platform on Sustainable Urban Mobility Plans.

[4] Strategic Plan (2016). New York City Department of Transportation, 2016.

[5] Lei 10.257/01, Regulamenta os arts. 182 e 183 da Constituição Federal, estabelece diretrizes gerais da política urbana e dá outras providências, Diário Oficial da União (de 10 de Julho de 2001).

[6] Lei 12.587/12, Institui as diretrizes da Política Nacional de Mobilidade Urbana, DIário Oficial da União (de 4 de Janeiro de 2012).

[7] Lei 13.089, Institui o Estatuto da Metrópole, altera a Lei no 10.257, de 10 de julho de 2001, e dá outras providências. (De 12 De Janeiro De 2015)

[8] Lei 13.683, Altera as Leis n ำ13.089, de 12 de janeiro de 2015 (Estatuto da Metrópole), e 12.587, de 3 de janeiro de 2012, que institui as diretrizes da Política Nacional de Mobilidade Urbana. (de 19 de Junho de 2018).

[9] Pinho, B., Brito, F.(2017). A urbanização da população brasileira: uma análise segundo o tamanho dos municípios. p.4. 
[10] BRASIL. Constituição (1988). Constituição da República Federativa do Brasil. Brasília: Senado, 1988.

[11] Queensland Government. Benefits of riding. Available in: <https://www.qld.gov.au/transport/public/bicycle-riding/benefits-of-riding> Access on: October, 2021.

[12] Lei 15.442. (Regulamentada pelo Decreto oㅗ 52.903/2012). Dispõe sobre a limpeza de imóveis, o fechamento de terrenos não edificados e a construção e manutenção de passeios, bem como cria o disque-calçadas; revoga as leis $\mathrm{n}^{\circ}$ 10.508, de 4 de maio de 1988, e n⿳0 12.993, de 24 de maio de 2000, (de 30 de dezembro de 2002).

[13] Reis, M. Urban Mobility: A Challenge for Public Managers.

[14] IPEA (2021). Tendências e desigualdades da mobilidade urbana no Brasil I : o uso do transporte coletivo e individual.

[15] Motte-Baumvol et al. Barriers and (im)mobility in Rio de Janeiro. Urban Studies Journal Limited 2015. SAGE.

[16] CENTRAL (2005) Plano Diretor de Transporte Urbano da Região Metropolitana do Rio de Janeiro: Resultatos da Pesquisa Origem e Destino. Rio de Janeiro: Governo do Estado do Rio de Janeiro.

[17] METRO (2017), METROPOLITAN REGION OF SÃO PAULO: Research Origin and Destination 2017. Governo de São Paulo. 